\title{
Measures of the home environment related to childhood obesity: a systematic review
}

\author{
Courtney A Pinard ${ }^{1,2, *}$, Amy L Yaroch ${ }^{1}$, Michael H Hart ${ }^{3}$, Elena L Serrano ${ }^{4}$, \\ Mary M McFerren ${ }^{4}$ and Paul A Estabrooks ${ }^{2}$ \\ 'Gretchen Swanson Center for Human Nutrition, 505 Durham Research Plaza, Omaha, NE 68105, USA: \\ ${ }^{2}$ Department of Human Nutrition, Foods and Exercise, Virginia Polytechnic Institute and State University, \\ Roanoke, VA, USA: ${ }^{3}$ Carilion Clinic, Roanoke, VA, USA: ${ }^{4}$ Department of Human Nutrition, Foods and Exercise, \\ Virginia Polytechnic Institute and State University, Blacksburg, VA, USA
}

Submitted 22 November 2010: Accepted 8 July 2011: First published online 7 September 2011

\begin{abstract}
Objective: Due to a proliferation of measures for different components of the home environment related to childhood obesity, the purpose of the present systematic review was to examine these tools and the degree to which they can validly and reliably assess the home environment.

Design: Relevant manuscripts published between 1998 and 2010 were obtained through electronic database searches and manual searches of reference lists. Manuscripts were included if the researchers reported on a measure of the home environment related to child eating and physical activity (PA) and childhood obesity and reported on at least one psychometric property.

Results: Of the forty papers reviewed, $48 \%$ discussed some aspect of parenting specific to food. Fifty-per cent of the manuscripts measured food availability/ accessibility, 18\% measured PA availability/accessibility, 20\% measured media availability/accessibility, $30 \%$ focused on feeding style, $23 \%$ focused on parenting related to PA and $20 \%$ focused on parenting related to screen time.

Conclusions: Many researchers chose to design new measures for their studies but often the items employed were brief and there was a lack of transparency in the psychometric properties. Many of the current measures of the home food and PA environment focus on one or two constructs; more comprehensive measures as well as short screeners guided by theoretical models are necessary to capture influences in the home on food and PA behaviours of children. Finally, the current measures of the home environment do not necessarily translate to specific subpopulations. Recommendations were made for future validation of measures in terms of appropriate psychometric testing.
\end{abstract}

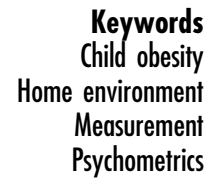

Keywords

environment

Psychometrics
The prevalence and severity of childhood overweight have increased significantly in the past three decades ${ }^{(1-3)}$. Negative sequalae from being overweight during childhood include being at a higher risk for a number of chronic and acute conditions ${ }^{(4)}$ as well as negative social and psychological outcomes ${ }^{(5)}$. The source for the majority of childhood obesity cases can be attributed to energy imbalance which has been linked to changes in the food and physical activity (PA) environments ${ }^{(6,7)}$.

The home environment has been documented as one that can either facilitate or inhibit healthful eating and PA, and caregivers play a key role in the development of the social and physical environment within a household ${ }^{(8,9)}$. From a social environment perspective, caregivers serve as role models for PA, dietary and media behaviours and influence the child's health behaviours and weight status through parenting strategies and feeding styles ${ }^{(10-21)}$. In addition, a child participates in more PA when a greater amount of space and active toys are available in the home ${ }^{(22,23)}$. Likewise, access to food items can impact consumption $^{(24,25)}$. Similarly, when more screen opportunities are available, children are more likely to engage in sedentary behaviour ${ }^{(26,27)}$.

Some researchers have conducted reviews of the home food environment ${ }^{(28,29)}$, while others have described measures of the community food environment ${ }^{(30)}$. There have also been a number of literature reviews on interventions targeting families to improve PA, diet and weight status in children ${ }^{(31-36)}$. In each case there has been a consistent call for assessing relevant home environment variables with validated measures. To develop an accurate assessment of the influence of the home environment it is important to have strong conceptual models and appropriate validation methodology ${ }^{(37)}$. Several groups of 


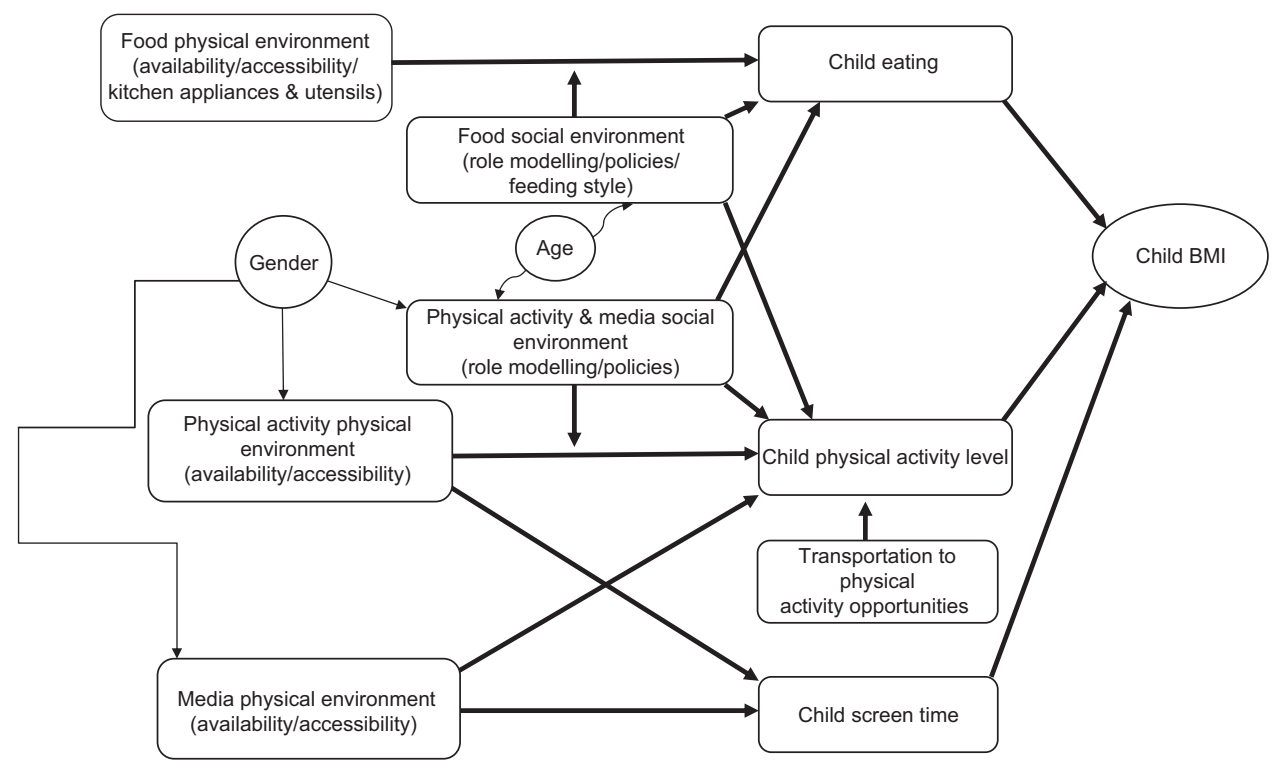

Fig. 1 Model of the home environment (modified from Gattshall et al. ${ }^{(38)}$ )

researchers have worked independently over the past few decades developing measures of caregiver influence on childhood obesity that are pertinent to specific programmes of research. As a result there is a wide variety of measures available that range in scope (i.e. constructs assessed). The disadvantage of having multiple measures of the home environment is the limited ability to compare results across studies. Owing to the proliferation of measures of different components of the home environment there is a need to provide clarity on which tools are available and the degree to which these can validly and reliably provide a comprehensive assessment of the home environment. Therefore, the purpose of the present systematic review is to examine the scope, reliability and validity of measurement tools of the home environment as it relates to childhood obesity.

\section{Design}

\section{Evidence acquisition}

Manuscripts published between 1990 and 2010 were searched for in the following databases: MEDLINE, PYSCLIT, CINAHL, ERIC and PsychINFO. The inclusive dates were selected since no review on measurement of the home environment has been conducted previously (only reviews of correlates and interventions) and we wanted to include the full spectrum of research in this area. Measurement work in this area conducted prior to 1990 is very limited, and measures from that time have generally been incorporated into existing literature. Citations of the articles resulting from the searches were also scanned for inclusion. Once relevant manuscripts validating measures were identified, further measurement articles were searched for using the title of the measure as a search term. Relevant studies were considered if the manuscript reported on a measure of the home environment related to children's diet, PA and weight status while also reporting at least one indicator of reliability or validity.

Measures were included if they were used in families with children between birth and 18 years of age, if they were completed by a child or an adult, and, for the latter, only if the adult measure was in reference to the home environment. The format could be paper-and-pencil, telephone/in-person interview, or completed by the researcher through direct observation.

Key terms utilized in the search included those defined by a Conceptual Model for Eating and Physical Activity Environment ${ }^{(38)}$ : food physical environment, the food social environment, PA physical environment, PA social environment, media physical environment and media social environment, as well as terms related to psychometric properties. In each case (i.e. food, PA, media), the physical environment included availability and accessibility and the social environment included caregiver role modelling and policies (Fig. 1).

Exclusion criteria were: (i) unpublished literature reviews; (ii) manuscripts utilizing only a qualitative methodology; (iii) those not specific to children; and (iv) those in language other than English. Further, articles were also excluded if they (v) did not report on at least one of the following psychometric properties: test-retest reliability, inter-rater reliability, internal consistency, criteria validity, convergent validity, divergent validity, predictive validity or factorial validity. Two authors reviewed each manuscript and coded for home environment constructs and psychometric testing in order to meet criteria for inclusion. 


\section{Results}

Overall, the combined search strategies identified 2606 unique manuscripts. After reviewing the abstracts of these studies, 2463 were eliminated; another 109 were eliminated upon reading the full manuscript. The main reason for excluding articles was that the study did not report on any psychometric properties of the measure (see Table 1 for a summary of psychometrics). An additional six manuscripts were added from screening reference lists, yielding a total of forty manuscripts included in the present review. Of these forty manuscripts overlapping constructs assessed included: $48 \%$ ( $n$ 19) some aspect of the food social environment ${ }^{(18,23,36,38,43,45,47,54-65)} ; 50 \%$ ( $n$ 20) food physical environment ${ }^{(18,36,38-47,54,55,57,59,61-63,65)}$; $18 \%\left(n\right.$ 7) PA physical environment ${ }^{(23,38,48,49,51,52,63)} ; 20 \%$ ( $n$ 8) media physical environment ${ }^{(23,27,38,49,51-53,63)} ; 30 \%$ ( $n$ 12) food social environment ${ }^{(38,57,60,63,66,67-70,72-74)} ; 23 \%$ (n 9) $)^{(23,38,48,52,54,56,60,63,64)}$ parenting related to PA; and $20 \%$ ( $n$ 8) PA and media social environment ${ }^{(23,27,38,52,53,60,63,64)}$

\section{Psychometric properties across measures}

Within each manuscript, internal consistency was the most commonly reported indicator of reliability (70\%) followed by test-retest reliability (38\%) and inter-rater reliability ( $8 \%)$. Only $5 \%$ reported on all three reliability indicators. Predictive and factorial validity were reported for $58 \%$ and $25 \%$ of the measures, respectively. However, convergent $(8 \%)$ and criteria (10\%) validity were rarely reported and no study provided all indicators of validity (Table 1).

\section{Food availability and accessibility}

Several researchers have developed measures of the availability and accessibility of healthy and less healthy foods in the home with most emphasis placed on fruits and vegetables ${ }^{(18,36,38-47,54,55,57,59,61-63,65)}$. While no gold standard exists for examining availability and accessibility of foods, some trials have used in-home inventories. This procedure involves a researcher checking food items that they observe as being present in the home ${ }^{(39,40)}$. Despite the validity of in-home inventories conducted by researchers, it is often not feasible to conduct this type of resource-intensive assessment and a checklist format completed by participants may be more practical. Many of the checklists focus on availability and accessibility of fruit and vegetables ${ }^{(11,40-45)}$, and some on less healthful foods ${ }^{(18)}$, while others include a full range of food groups to reflect the typical US diet ${ }^{(46)}$. Availability has also been assessed most basically by asking whether caregivers purchase foods on their child's request and if foods are visible $^{(47)}$. When compared with consumption behaviours, the availability and accessibility of specific foods were related ${ }^{(11,18,40-45,47)}$.

Fruit and vegetable availability and accessibility checklists have displayed moderate internal consistency even when availability and accessibility scales are collapsed (i.e. median $\alpha=0 \cdot 69)^{(40)}$. When compared with researcher observation, sensitivity and specificity were generally supported with higher false positive rates in the case of perishable items which tend to be consumed at a faster rate ${ }^{(41)}$. Additionally, some studies indicate that caregivers are more likely to report greater availability of fruits and vegetables than their children and that self-reported intake is more likely to correlate with the children's report ${ }^{(42,43)}$. Furthermore, the scales showed improved internal consistency when children reported $(\alpha=0 \cdot 82-0 \cdot 92)^{(42,45)}$. In the case of a more comprehensive checklist, agreement between the researcher and the participant (criterion validity) was substantial, supporting measure validity ${ }^{(46)}$.

\section{Physical activity availability and accessibility}

Seven studies assessed PA availability and accessibility. Checklists are a commonly used method to assess these components of the home environment ${ }^{(23,38,48,49,51,52,63)}$. In one comprehensive and well-validated measurement of the PA environment Sirard et al. ${ }^{(49)}$ asked participants to record whether they had specific equipment in categories and each item was multiplied by the score of accessibility. From this, researchers could rank the overall quality of the home environment score by a ratio of activity-to-media equipment ${ }^{(49)}$. The researchers recommended that this instrument be used in conjunction with other measurements (e.g. home food availability) to identify obesogenic home environments ${ }^{(49)}$.

While these PA scales displayed moderate to high testretest reliability (intra-class correlation coefficient $($ ICC $)=0 \cdot 72-0 \cdot 99)^{(48,49)}$ one exception was for having a covered area outdoors and having active toys, where the internal consistency was low to moderate $(\alpha=$ $0 \cdot 43-0 \cdot 77)^{(48)}$. Criterion validity, established by comparing the responses from the participant to those that were observed by the researcher, was generally high (Pearson $r=0 \cdot 67-0 \cdot 98)^{(49)}$.

\section{Media equipment availability}

In a technology- and media-driven world, sedentary activities are often determined by the opportunities the child has to engage in screen behaviours ${ }^{(50)}$. Typically caregivers complete an inventory of items in their home that may encourage or support children's screenbased behaviours: television, digital video disc player, video games and others ${ }^{(27,51,52)}$. Similar to the assessment of fruit and vegetable availability, some researchers take a simple approach and inquire how many televisions are in the home and whether the child has a television in his/her bedroom ${ }^{(52,53)}$. With these measures, only the test-retest reliability was reported and the agreement between tests was high in each case $\left(91-99 \%\right.$ agreement $^{(27)}$, ICC $=0.54-0.92^{(51)}$, ICC $=$ $\left.0 \cdot 79-0 \cdot 90^{(52)}\right)$. 
Table 1 Description of measures and psychometric properties

\begin{tabular}{|c|c|c|c|c|c|c|c|c|c|c|c|c|}
\hline Authors & Construct assessed & Participants & $\begin{array}{l}\text { Sample low- } \\
\text { income }\end{array}$ & Culture/ethnicity & $\begin{array}{l}\text { Inter-rater } \\
\text { reliability }\end{array}$ & $\begin{array}{l}\text { Test-retest } \\
\text { reliability }\end{array}$ & $\begin{array}{l}\text { Internal } \\
\text { consistency }\end{array}$ & Criteria validity & $\begin{array}{l}\text { Convergent } \\
\text { validity }\end{array}$ & Predictive validity & $\begin{array}{l}\text { Factorial } \\
\text { validity }\end{array}$ & $\begin{array}{l}\text { Content } \\
\text { validity }\end{array}$ \\
\hline \multicolumn{13}{|c|}{ FOOD PHYSICAL AND SOCIAL MEASURES } \\
\hline Cullen et al. ${ }^{(57)}$ & $\begin{array}{l}\text { FV availability and } \\
\text { accessibility, feeding style, } \\
\text { parental role modelling and } \\
\text { policies of healthy eating }\end{array}$ & $\begin{array}{l}\text { 4th-6th grade } \\
\text { students }(n 230)\end{array}$ & No & $\begin{array}{l}25 \% \text { African American, } \\
29 \% \text { European } \\
\text { American, } \\
37 \% \text { Mexican } \\
\text { American, } 9 \% \text { Asian }\end{array}$ & Not assessed & $\begin{array}{l}\text { Pearson } \\
r=0.30-0.73\end{array}$ & $\alpha=0 \cdot 19-0 \cdot 88$ & Not assessed & Not assessed & Not assessed & $\begin{array}{l}\text { Account for } \\
11 \% \text { and } 4 \% \\
\text { variability }\end{array}$ & Not assessed \\
\hline Campbell et al. ${ }^{(18)}$ & $\begin{array}{l}\text { Unhealthy food availability, } \\
\text { policies for healthy eating } \\
\text { (meal and eating } \\
\text { formality, parenting } \\
\text { consistency) }\end{array}$ & $\begin{array}{l}\text { Parents of adolescents } \\
\text { mean age } 13 \cdot 0 \\
(\mathrm{sD} 0 \cdot 2) \text { years }(n 347)\end{array}$ & No & $\begin{array}{l}\text { Not reported (study } \\
\text { conducted in Australia) }\end{array}$ & Not assessed & Not assessed & $\alpha=0.44-0.82$ & Not assessed & Not assessed & $\begin{array}{l}\text { Regression models } \\
\text { significantly predicted } \\
\text { sweetened beverage } \\
\text { consumption and } \\
\text { sweet snack } \\
\text { consumption } \\
\text { accounting for } \\
9-22 \% \text { of the } \\
\text { variance }\end{array}$ & Not assessed & Not assessed \\
\hline Vereecken et $a^{(58)}$ & $\begin{array}{l}\text { Parental policies and role } \\
\text { modelling regarding } \\
\text { eating }\end{array}$ & $\begin{array}{l}\text { Parents of pre-school } \\
\text { children in Belgium, } \\
\text { mean age } 4.7 \text { (sD 1.0) } \\
\text { years }(n 346)\end{array}$ & No & $\begin{array}{l}\text { Not reported (study } \\
\text { conducted in Belgium) }\end{array}$ & Not assessed & Not assessed & $\alpha=0.71-0.94$ & Not assessed & Not assessed & $\begin{array}{l}\text { Spearman correlations } \\
\text { between intake and } \\
\text { variables, } \\
r=-0.16-0.59\end{array}$ & Not assessed & Not assessed \\
\hline Campbell et al. ${ }^{(59)}$ & $\begin{array}{l}\text { Parental role modelling and } \\
\text { policies for healthy eating, } \\
\text { FV availability }\end{array}$ & $\begin{array}{l}\text { Parent-child dyads, } \\
\text { mean age of children } \\
6.1 \text { years }(n 560)\end{array}$ & $\begin{array}{l}\text { Yes, range of } \\
\text { SES }\end{array}$ & $\begin{array}{l}\text { Not reported (study } \\
\text { conducted in Australia) }\end{array}$ & Not assessed & Not assessed & $\alpha=0.64-0.90$ & Not assessed & Not assessed & $\begin{array}{l}\text { Regression accounted } \\
\text { for } 2 \cdot 8-11 \cdot 7 \% \text { of the } \\
\text { variance in outcome } \\
\text { variables }\end{array}$ & $\begin{array}{l}\text { Support for a } \\
\text { 9-factor model }\end{array}$ & Not assessed \\
\hline Young et al. ${ }^{(36)}$ & $\begin{array}{l}\text { FV availability, policies for } \\
\text { healthy eating, parental } \\
\text { modelling }\end{array}$ & $\begin{array}{l}\text { Students aged 12-16 } \\
\text { years }(n \text { 366) }\end{array}$ & $\begin{array}{l}33 \% \text { reported } \\
\text { free or reduced- } \\
\text { price lunch }\end{array}$ & $\begin{array}{l}82 \% \text { Caucasian, } \\
6 \% \text { African American, } \\
4 \% \text { multi-racial, } 3 \% \\
\text { Asian, } 3 \% \text { Hispanic, } \\
3 \% \text { American Indian }\end{array}$ & Not assessed & Not assessed & $\alpha=0.65-0.85$ & Not assessed & Not assessed & $\begin{array}{l}\text { Regression supported } \\
\text { variables predicting FV } \\
\text { consumption } \\
\text { accounting for } 39 \% \text { of } \\
\text { the variance }\end{array}$ & Not assessed & Not assessed \\
\hline $\begin{array}{l}\text { Neumark-Sztainer } \\
\text { et al. }{ }^{(61)}\end{array}$ & $\begin{array}{l}\text { Parental policies and role } \\
\text { modelling of healthy } \\
\text { eating, availability of FV }\end{array}$ & $\begin{array}{l}\text { Children and } \\
\text { adolescents at middle } \\
\text { and high schools, } \\
\text { mean age } 14 \cdot 9 \\
\text { (SD 1.7) years ( } n \text { 3957) }\end{array}$ & $\begin{array}{l}\text { School districts } \\
\text { serving SES- } \\
\text { diverse } \\
\text { populations }\end{array}$ & $\begin{array}{l}\text { 48.5\% Caucasian, } 9.0 \% \\
\text { African American, } \\
19.2 \% \text { Asian American, } \\
5.8 \% \text { Hispanic, } \\
3.5 \% \text { Native American, } \\
3.9 \% \text { mixed/other }\end{array}$ & Not assessed & Not assessed & $\alpha=0.43-0.81$ & Not assessed & Not assessed & $\begin{array}{l}\text { Pearson correlations } \\
\text { with outcome } \\
\text { variables, } \\
r=-0.09-0.33\end{array}$ & $\begin{array}{l}\text { Support for a } \\
\text { 13-factor } \\
\text { solution }\end{array}$ & Not assessed \\
\hline Wilson et al. ${ }^{(65)}$ & $\begin{array}{l}\text { FV availability and } \\
\text { accessibility, parental } \\
\text { policies for health eating }\end{array}$ & $\begin{array}{l}\text { Children aged 10-12 } \\
\text { years }(n \text { 141) }\end{array}$ & No & No information & Not assessed & ICC $=0.47-0.66$ & $\alpha=0.50-0.80$ & Not assessed & Not assessed & Pearson $r=0.36-0.48$ & Not assessed & Not assessed \\
\hline Rosno et al. & Food (all types) availability & $\begin{array}{l}\text { Parents of overweight } \\
\text { children aged 6-18 } \\
\text { years, mean age 11.6 } \\
\text { (SD 2.5) years ( } n 63)\end{array}$ & No & $\begin{array}{l}83 \% \text {, European } \\
\text { American, } 6 \% \text { African } \\
\text { American, } 4 \% \text { Native } \\
\text { American, } 8 \% \text { 'other' }\end{array}$ & $\begin{array}{l}95 \% \text { agreement } \\
\text { between } \\
\text { researchers }\end{array}$ & Not assessed & Not assessed & Not assessed & Not assessed & Not assessed & Not assessed & Not assessed \\
\hline Hearn et al..$^{(40)}$ & $\begin{array}{l}\text { FJV availability and } \\
\text { accessibility }\end{array}$ & $\begin{array}{l}\text { Parents of elementary- } \\
\text { school children }\end{array}$ & No & $\begin{array}{l}\text { Not reported (study } \\
\text { conducted in Australia) }\end{array}$ & Not assessed & Not assessed & $\alpha=0.69$ & Not assessed & Not assessed & $\begin{array}{l}\text { Pearson correlation } \\
\text { to intake, } \\
r=0.11-0.54\end{array}$ & Not assessed & Not assessed \\
\hline Marsh et al. (41) & FV availability & $\begin{array}{l}\text { Parents of } 4 \text { th-6th } \\
\text { grade children } \\
\text { interviewed; mean age } \\
\text { of parents } 42 \cdot 1 \text { years } \\
(n 48)\end{array}$ & No & $\begin{array}{l}48 \% \text { white, } 33 \% \\
\text { Mexican American, } 8 \% \\
\text { black, } 11 \% \text { Asian/other }\end{array}$ & Not assessed & Not assessed & Not assessed & $\begin{array}{l}\text { Sensitivity and spec- } \\
\text { ificity }=34 \cdot 5 \cdot-42 \cdot \cdot \% \% \\
\text { (75.9\% agreement; } \\
\text { false positive }= \\
19 \cdot 4-20 \cdot 6 \% \text {; false } \\
\text { negative }=3 \cdot 6-4 \cdot 1 \%)\end{array}$ & Not assessed & Not assessed & Not assessed & Not assessed \\
\hline Cullen et al. ${ }^{(42)}$ & $\begin{array}{l}\text { FV availability and } \\
\text { accessibility }\end{array}$ & $\begin{array}{l}\text { 4th-6th grade children } \\
(n \text { 225) and their } \\
\text { parents }(n 88) ; \text { mean } \\
\text { age of parents } \\
40 \text { (sD 6.6) years }\end{array}$ & No & $\begin{array}{l}\text { Children with non- } \\
\text { participating parents } \\
\text { (26\% African } \\
\text { American, } 31 \% \\
\text { European American, } \\
31 \% \text { Hispanic, } 12 \% \\
\text { Asian); children with } \\
\text { participating parents } \\
\text { (22\% African American, } \\
32 \% \text { European } \\
\text { American, } 33 \% \\
\text { Hispanic, } 13 \% \text { Asian) }\end{array}$ & Not assessed & Not assessed & $\alpha=0.30-0.85$ & Not assessed & Not assessed & $\begin{array}{l}\text { For children with high } \\
\text { FJV preferences, } \\
\text { FJV availability } \\
\text { predicted } \\
\text { consumption; both } \\
\text { availabiliti and } \\
\text { accessibility were } \\
\text { significantly related to } \\
\text { consumption for } \\
\text { children with low FJV } \\
\text { preferences }\end{array}$ & Not assessed & Not assessed \\
\hline
\end{tabular}




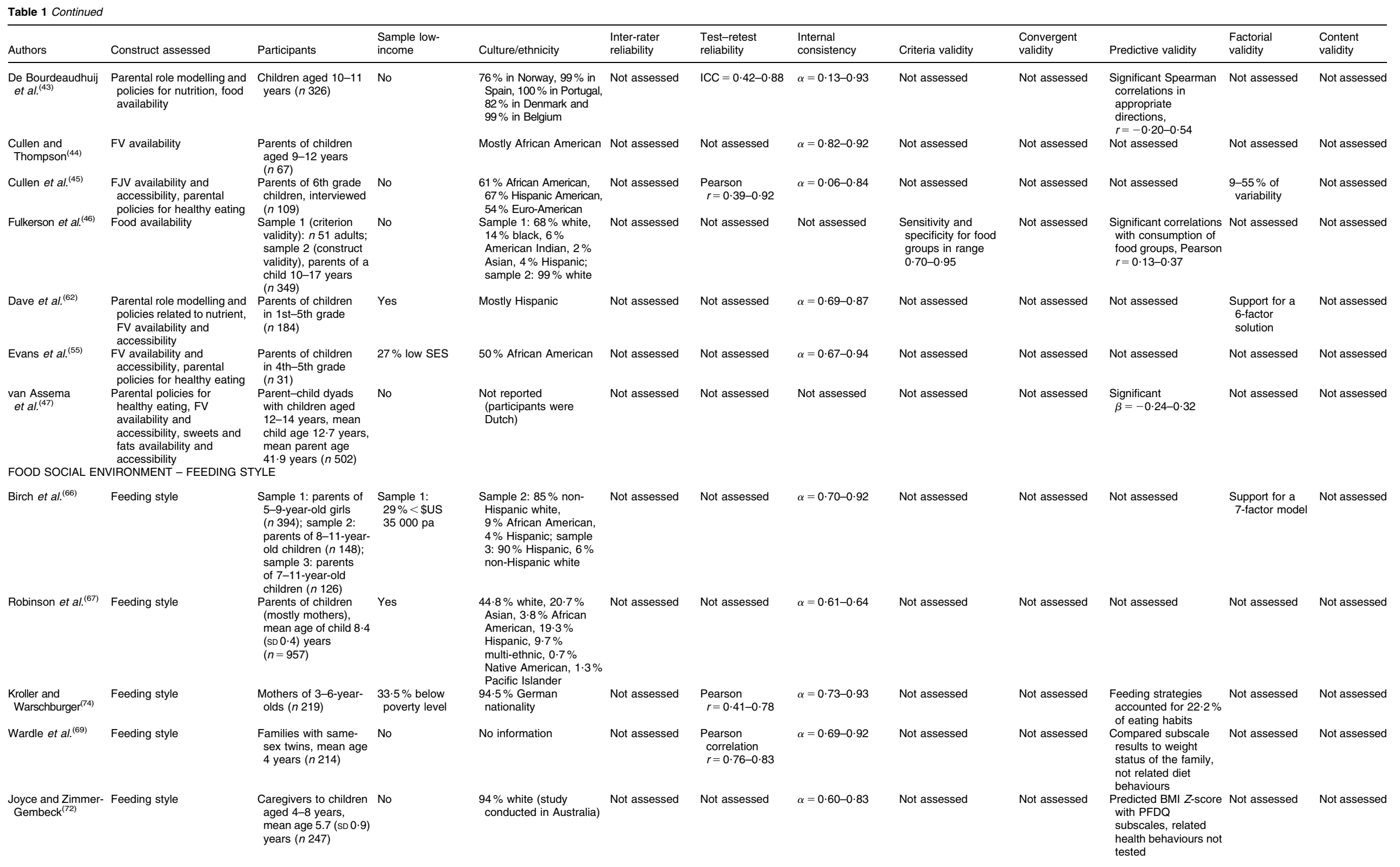


Table 1 Continued

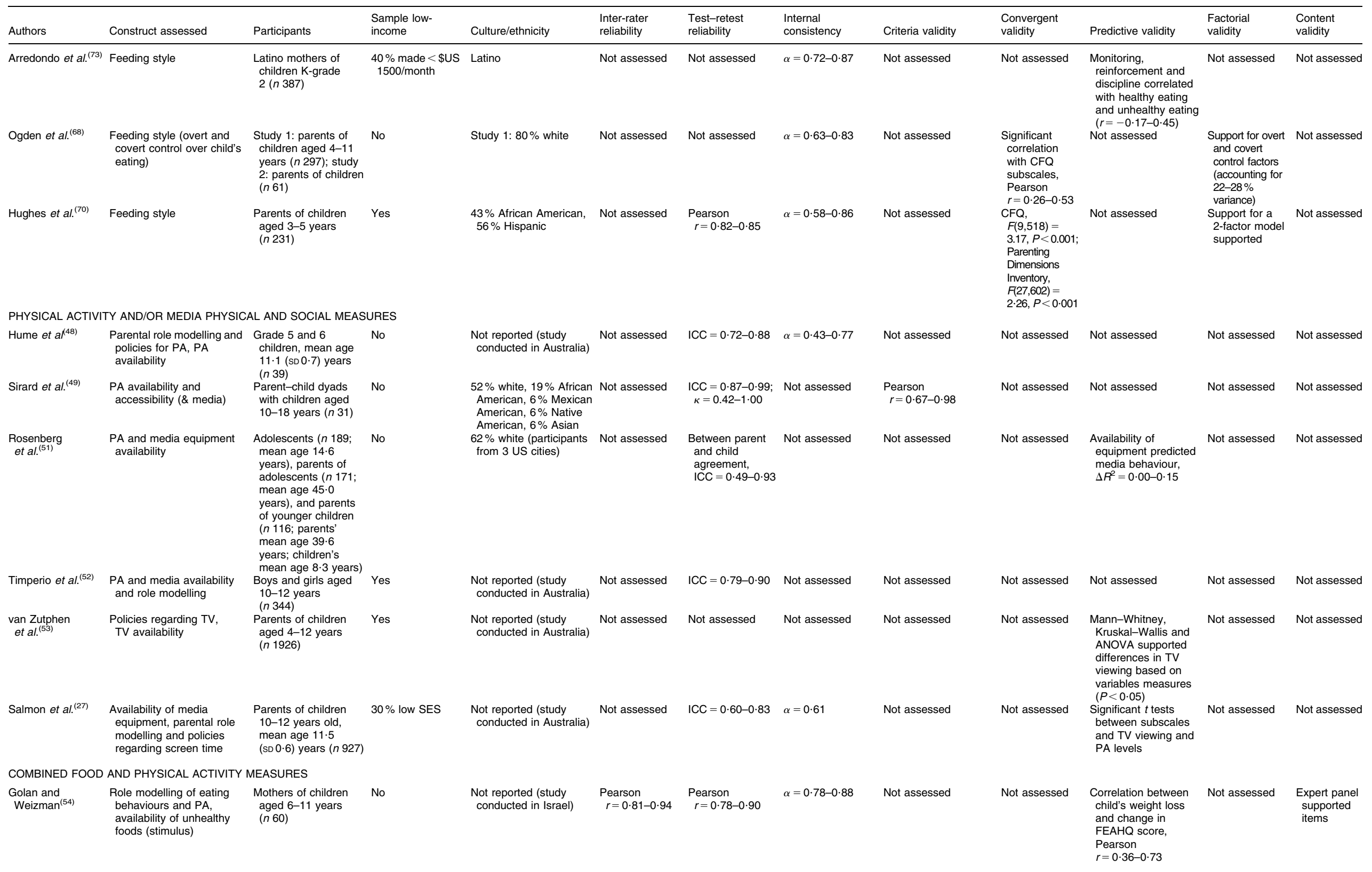


Table 1 Continued

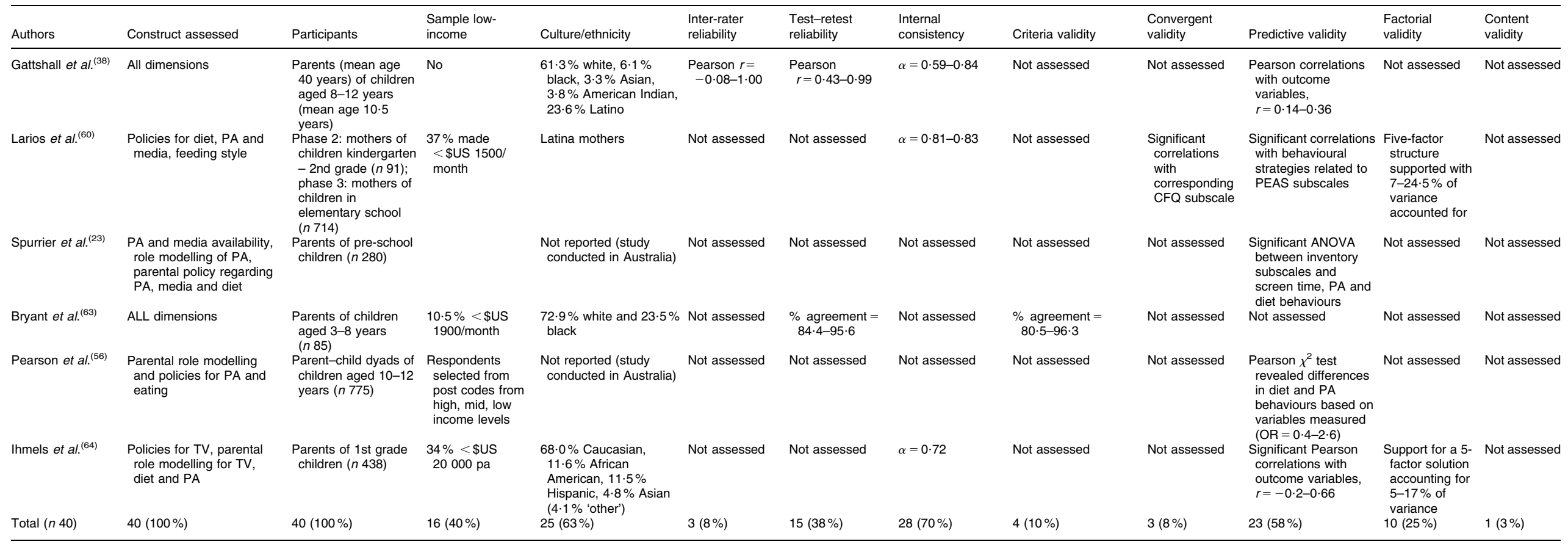

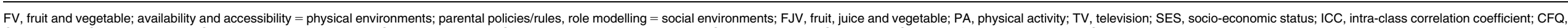
FV, fruit and vegetable; availability and accessibility = physical environments; parental policies/rules, role modelling = social environments; FJV, fruit, juice and vegetable; PA, physical activity; TV, telev
Child Feeding Questionnaire; PFDQ, Parent Feeding Dimensions Questionnaire; FEAHQ, Family Eating and Activity Habits Questionnaire; PEAS, Parenting Strategies for Eating and Activity Scale. 


\section{Role modelling and policies}

Beyond the physical environment in the home, caregivers are also responsible for establishing the social environment that influences health behaviours ${ }^{(8,38,54)}$. Some researchers focus on social support for healthy eating and $\mathrm{PA}^{(36,55)}$, while others use different terminology for a similar construct, such as asking children how often they were active with family members and if somebody at home encouraged them to be active ${ }^{(54)}$. Another method to consider how caregivers can socially influence health behaviours in their children is to examine rules and policies that they implement, including meal formality and consistency ${ }^{(18,27,47)}$ as well as role modelling of healthy eating and $\mathrm{PA}^{(51,56-59)}$.

Overall, caregiver role modelling, support and rules and policies were all significant predictors of dietary intake and PA behaviours ${ }^{(18,27,36,47,48,51,56-58)}$. Specifically, rules, policies and social support regarding media supported less screen time in children. Caregiver role modelling is a consistent correlate of positive health behaviours in children and not necessarily within the same behaviour domain (i.e. diet or PA). Internal consistencies ranged from moderate to high $(\alpha=0 \cdot 64-0 \cdot 94)^{(18,27,36,48,57,58)}$ and testretest reliability was high $(\text { ICC }=0 \cdot 61-0 \cdot 90)^{(27,48)}$.

A good example of a measure developed and validated with a focus on caregiver role modelling and policies is the Parenting Strategies for Eating and Activity Scale $(\text { PEAS })^{(60)}$. The PEAS was tested in a sample of Latino women to evaluate a wider range of parenting strategies and demonstrated moderate to high internal consistency $(\alpha=0 \cdot 81-0 \cdot 82)^{(60)}$. Construct validity was established for the PEAS by correlating the subscales with the appropriate subscales of a child feeding questionnaire.

\section{Multiple components of the bome environment}

In attempts to assess multiple components of the home environment (e.g. those outlined in the Conceptual Model for Eating and Physical Activity Environment), several researchers have developed measurement tools with multiple subscales. These measurement tools contain a range of constructs and psychometric qualities which make them appropriate for use in different instances.

For comprehensive assessments of both environmental and behavioural components, Neumark-Sztainer et al. ${ }^{(61)}$ developed a 221-item questionnaire assessing a range of socio-environmental, personal and behavioural factors associated with dietary intake among adolescents ${ }^{(61)}$. Items identified to be relevant for the current review were availability of vegetables and family meal patterns as a source of caregiver role modelling, which demonstrated moderate internal consistency $(\alpha=0 \cdot 63-0 \cdot 78)^{(61)}$ and test-retest reliability $(r=0 \cdot 66-0 \cdot 69)^{(17)}$.

An example of a tool to assess multiple attitudinal and caregiver practices is the Home Nutrition Questionnaire developed by Dave et ll $^{(62)}$. Six factors were identified in a low-income and mainly Hispanic population: child's preferences for fruit and vegetables, caregiver practices that promote fruit and vegetables, caregiver role modelling, perceived cost of fruit and vegetables, perceived benefits of fast food and eating while watching television. The internal consistency of the scales was moderate to high $(\alpha=0 \cdot 69-0 \cdot 87)^{(62)}$.

Bryant et $a l^{(63)}$ assessed multiple components of the home environment in their Healthy Home Survey (HHS) including food, media and PA availability and accessibility, caregiver role modelling and policies for eating and PA. The test-retest was high for most items except fresh fruit. Validity (in-home assessments) estimates were lowest for sweet snacks $(\kappa=0 \cdot 00)$ and fresh vegetables $(\kappa=0 \cdot 23)$ and highest for frozen fruit $(\kappa=0 \cdot 87)$ and dried fruit $(\kappa=0 \cdot 85)$. Food accessibility showed good reliability (biased-adjusted kappa $($ PABAK $)=0.96)$ and poor validity (PABAK $=0 \cdot 85$ ). The results of the HHS suggest that measurement of variety and quantity of foods may be a better indicator than presence or absence alone.

Finally, Gattshall et $a l^{(38)}$ developed and tested the Home Environment Survey (HES) which assesses a breadth of home environment variables including the availability and accessibility of food and PA, caregiver role modelling and policies for healthy eating and PA. The internal consistencies were moderate to high for these scales $(\alpha=0 \cdot 66-0 \cdot 84)$, except for the accessibility of fat and sweets scale $(\alpha=0 \cdot 59)$ and accessibility for fruits and vegetables was reduced to a single item due to poor reliability. As the researchers suggest, perhaps the internal consistency was lower on these subscales because they were too broad (i.e. 'How often do you store high-calorie foods in a place that was known but not seen?'). Another theory could be that that the items were too embedded (they ended up being confusing for the participant because they had too much information 'embedded', so that the participant could not cognitively interpret the construct). Test-retest and inter-rater reliabilities were low to high $(r=0 \cdot 49-0.99$ and $r=0 \cdot 22-0 \cdot 70$, respectively), indicating some differences between caregiver report of the home environment. The subscales showed strong predictive validity for both the child and caregiver.

\section{Screeners or short measures}

Short screeners are useful as a brief and easy-to-administer tool to assess the overall home environment 'at a glance', giving the researcher a gross estimate of the family's home environment. Only three screeners are described in the literature which assess the overall impact of the home environment related to childhood obesity. Ihmels et al. ${ }^{(64)}$ developed and tested the Family Nutrition and Physical Activity (FNPA) screening tool for familial environment and behaviours that may predispose a child to become overweight. This is a twenty-one-item screening tool was developed based on established Evidence Analyses procedures of the American Dietetic Association, which demonstrates high content validity. The FNPA assesses 
caregiver role modelling of nutrition and PA, television availability and dietary/nutrition/sleep behaviours. Similarly, Wilson et $a l^{(65)}$ developed and tested the Child Nutrition Questionnaire which assesses fruit and vegetable availability and accessibility and policies for healthy eating in fourteen items. They found moderate test-retest reliability in ten of the twelve scales and low to moderate internal consistencies $(\alpha=0 \cdot 50-0 \cdot 80)$. Golan and Weizman ${ }^{(54)}$ created the Family Eating and Activity Habits Questionnaire (FEAHQ) and included the availability of unhealthy foods as an indicator of stimulus exposure in addition to child eating behaviours. The eight items assessing availability had moderate internal consistency $(\alpha=0 \cdot 78)$ and the test-retest was acceptable.

\section{Feeding style}

Feeding style has received much attention in research, largely separate from the home environment, but is relevant to the social food environment as it is closely related to policies for healthy eating. Birch et al. ${ }^{(66)}$ established the Child Feeding Questionnaire (CFQ), a seven-factor model which focused on two broad categories: (i) parental perceptions and (ii) concerns for and use of child feeding practices. Seven factors included: perceived responsibility for the child's weight, perceived parent weight, perceived child weight, concern about child weight, pressure to eat, restriction and monitoring, and all subscales had high internal consistency $(\alpha \geq 0 \cdot 71)^{(66)}$.

Many researchers have modified or simply used certain subscales of the original CFQ based upon their research questions. In the interest of having a child's perspective on feeding style, the CFQ has been adapted from a parentreported tool to a child-reported one ${ }^{(18)}$. With an emphasis on controlling feeding styles in a low-income population, it was concluded that previous findings of control being related to greater body weight of the child may not apply to younger children (aged 8-9 years) of diverse ethnic and sociodemographic backgrounds ${ }^{(67)}$. The internal consistency of the control scale was low $(\alpha=0 \cdot 61)^{(67)}$. Similarly, Ogden et al. ${ }^{(68)}$ wanted to expand the concept of child feeding to differentiate between overt and covert control, with overt control defined as controlling a child's food intake in a way that the child can detect while covert control cannot be detected by the child ${ }^{(68)}$. The two control scales had adequate internal consistency $(\alpha=0 \cdot 78-0 \cdot 83)^{(68)}$.

Beyond controlling feeding styles, some researchers have developed items to reflect slightly different constructs from the CFQ: emotional feeding, instrumental feeding, prompting or encouraging child to eat, and control over eating ${ }^{(69)}$. These four subscales demonstrated moderate internal consistency $(\alpha=0 \cdot 65-0 \cdot 85)$ and test-retest reliability $(r=0 \cdot 67-0 \cdot 83)^{(69)}$. Hughes et al. ${ }^{(70)}$ wanted to expand the concept of child feeding to include dimensions of Maccoby and Martin's ${ }^{(71)}$ typology of general parenting (demandingness and responsiveness) regarding the child's eating: parent-centred and childcentred strategies ${ }^{(70)}$. These two scales revealed high test-retest reliability $(r=0 \cdot 82-0 \cdot 85)$ and convergent validity was supported by the subscales being correlated with the appropriate subscales on the $\mathrm{CFQ}^{(70)}$. Similarly, Joyce and Zimmer-Gembeck ${ }^{(72)}$ assessed multiple parental feeding-specific dimensions including: supportiveness, structure, coerciveness and chaos $(\alpha=0 \cdot 72-0 \cdot 92)$.

Arredondo et al. $^{(73)}$ adapted the CFQ based upon focus groups with Latina mothers and yielded a five-factor measure: monitoring, discipline, control, limit setting and reinforcement $(\alpha=0 \cdot 72-0 \cdot 87)$. Kroller and Warschburger ${ }^{(74)}$ tested parental feeding strategies through translated items from two measures assessing restriction, monitoring, pressure, rewarding, child's control and modelling. These scales demonstrated adequate internal consistency $(\alpha=0 \cdot 75-$ $0 \cdot 93$ ) and moderate test-retest reliability (Pearson $r=0 \cdot 41-0 \cdot 78)^{(74)}$.

\section{Discussion}

Several reviews of childhood obesity interventions focusing on the home or caregiver involvement have been conducted $^{(31,34)}$. These reviews conclude that behavioural interventions including the family are effective; however, the mechanism of change is unclear ${ }^{(75)}$. In order for research in the area of the home environment and childhood obesity to move forward a greater emphasis on appropriate measurement is necessary. The current review assessed measures of the home environment in a broad sweep of the literature in order to gain a better understanding of appropriate measures of these complex constructs using a conceptual model as a guiding framework ${ }^{(38)}$. The literature review resulted in forty manuscripts describing measurement of different aspects of the home environment. The sample would have been much larger had we included manuscripts describing measurements that did not have any supporting reliability and validity; however, it was the purpose of the review to describe those measures which have some psychometric evaluation. The reader is directed to Table 1 as a resource tool to identify and evaluate the measurement tools available assessing different components of the home environment. Table 1 describes the measurement tools, identifies which constructs are assessed, which population the tool was validated with, whether this sample included specific sub-populations (i.e. low-income, racial/ethnic minorities) and the results of any psychometric testing.

The objective of the current review was to assess the degree to which measurement tools of the home environment can validly and reliably provide assessment. The overall finding was that although many of the reviewed measurement tools have supporting psychometric properties, there is no consistency across similar types of measures (i.e. checklists $v$. subscales $v$. screeners) as to which psychometric properties are appropriate as supporting evidence. For example, Bollen and Lennox 
warn that not all types of scales lend themselves to item covariance (i.e. internal consistency) ${ }^{(76)}$. Further, causal indicators of the latent construct do not necessarily need to be related to each other to provide meaningful assessment of the latent construct ${ }^{(76)}$. Table 2 was developed as part of the review to help guide researchers in the validation of measurement tools utilizing specific types of psychometric properties for certain types of scales for assessing the home environment (checklists, subscales or screeners). One method of validation that is often overlooked is assessing other variables that are effects, or outcomes, of the latent construct $^{(76)}$. This method should be employed more often when building measurement and theoretical models in concert with survey development and validation.

In conducting the present review, it was evident that many researchers chose to design new measures for their studies and often the tools employed were brief with a lack of reporting of psychometric properties. This is also evident in the number of measures that researchers have employed that were not included in the current review as they did not report any psychometric properties. When considering the psychometric findings, the data support the conclusion that the measures have adequate reliability, but that evidence of validity is more equivocal. It is important to note that although a measure is reliable, that does not support the validity. Based upon the results of the current review, there is a need for more measurement studies assessing the validity of measurement tools.

While additional validity studies are needed, it is also critical to test existing measures in diverse samples as current measures of the home environment may not necessarily translate to specific sub-populations. The majority of existing efforts to validate home environment measures did not seek out specific populations that experience obesity at disproportionate rates, such as low-income and/or ethnic/ minority families. Future measurement efforts may want to focus on assessing the home environment of these harderto-reach families in order to garner a better understanding of the factors that influence these important health behaviours, especially as many obesity prevention interventions currently target at-risk populations.

Despite limitations across studies, several researchers have designed and tested aspects of the home environment. For example, Bryant et al. ${ }^{(29)}$ and Gattshall et al. ${ }^{(38)}$ have both put forth two comprehensive measures of the home environment assessing both social and physical environments that influence childhood obesity. Conversely many research studies call for brevity in measurement, and screening tools that asses key components of the home environment that place children at risk for becoming obese have utility. Currently there are only three screening tools are evident in the literature. Further research that expands these measures is warranted.

Although closely related to policies and role modelling of healthy eating and PA, child feeding is a unique construct which has been studied extensively. The CFQ

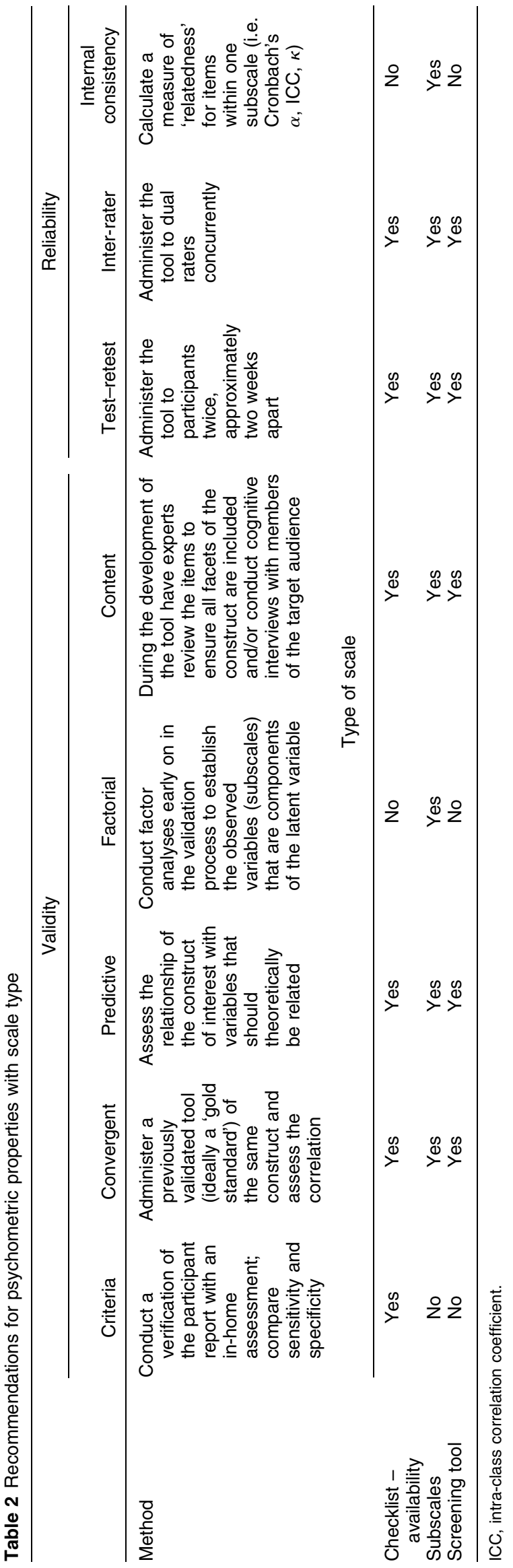


has been employed, manipulated and tested by a number of researchers, as have the factors involving caregiver perceptions and concerns regarding child feeding practices ${ }^{(65)}$. Researchers should consider child feeding in their assessment of the social home environment related to nutrition. In addition to social aspects of the home environment, reporting of physical components by adults $v$. children has yielded interesting results. A few studies showed that when children reported availability of food items in the home, the internal consistency improved. One explanation is that caregivers may be more biased because they are motivated to appear as good providers of more healthful food options for their children. However, this requires further investigation along with validation studies.

The conceptual model guiding the present review ${ }^{(38)}$ did not include the influence of siblings on behaviours within the home. Future research on the home environment may choose to include sibling variables and acknowledge the complexity of familial influences. However, a strength of the review is that it was guided by a theoretical model that was expanded (e.g. feeding style incorporated), resulting in a comprehensive review of measures of the home environment related to childhood obesity. Multiple measures assessing similar constructs of the home environment currently hinder a comparative analysis across studies. Many of the current measures of the home food and PA environment focus on one or two constructs; more comprehensive measures are necessary to capture influences in the home on food and PA behaviours of children. This calls for a more concerted effort to gain a better understanding of familial influences on childhood obesity. Once consistency in the measurement of the family and home environment has been established, the quality of the validation studies should be assessed.

\section{Conclusions}

The current review provides a summary and evaluation of measurement tools available in the assessment of the home environment related to childhood obesity. Practitioners can reference the available tools for use in assessing programmatic outcomes while researchers can review the available tools and use the guidance provided for future validation studies. The results of the current review clearly identify a need for comprehensive tools, assessment of specific constructs and short screeners. If more deliberate action is taken to improve and validate existing tools and create new ones with greater emphasis on appropriate measurement models and forms of psychometric testing, the evidence base behind childhood obesity interventions and epidemiological studies focusing on the home environment will be advanced.

\section{Acknowledgements}

This research received no specific grant from any funding agency in the public, commercial or not-for-profit sectors. The authors declare no conflicts of interests. All authors contributed to the development and production of the literature review. C.A.P. conducted the literature review under the guidance of P.A.E., M.M.M., M.H.H. and E.L.S.; P.A.E., M.M.M., M.H.H. and E.A.S. also edited the manuscript. A.L.Y. provided direction in terms of synthesizing the literature and edits overall.

\section{References}

1. Ogden CL, Carroll MD, Curtin LR et al. (2010) Prevalence of high body mass index in US children and adolescents, 2007-2008. JAMA 303, 242-249.

2. Ogden CL, Carroll MD \& Flegal KM (2008) High body mass index for age among US children and adolescents, 2003-2006. JAMA 299, 2401-2405.

3. Wang Y \& Lobstein T (2006) Worldwide trends in childhood overweight and obesity. Int J Pediatr Obes 1, 11-25.

4. Lobstein T, Baur LA \& Jackson-Leach R (2010) The childhood obesity epidemic. In Preventing Childbood Obesity: Evidence Policy and Practice, pp. 3-14 [E Waters, BA Swinburn, JC Seidell et al., editors]. Oxford: Blackwell Publishing.

5. Lee YS (2009) Consequences of childhood obesity. Ann Acad Med Singapore 38, 75-77.

6. Dehghan M, Akhtar-Danesh N \& Merchant A (2005) Childhood obesity, prevalence and prevention. Nutr J 4, 24.

7. Spiegelman BM \& Flier JS (2001) Obesity and the regulation of energy balance. Cell 104, 531-543.

8. Golan M \& Weizman A (2001) Familial approach to the treatment of childhood obesity: conceptual model. J Nutr Educ 33, 102-107.

9. Rosenkranz RR \& Dzewaltowski DA (2008) A model of the home food environment pertaining to childhood obesity. Nutr Rev 66, 123-140.

10. Pugliese J \& Tinsley B (2007) Parental socialization of child and adolescent physical activity: a meta-analysis. J Fam Psychol 21, 331-343.

11. Hood MY \& Ellison RC (2000) Parental eating attitudes and the development of obesity in children. The Framingham Children's Study. Int J Obes Relat Metab Disord 24, 1319-1325.

12. Fisher JO, Mitchell DC, Wright HS et al. (2002) Parental influences on young girls' fruit and vegetable, micronutrient, and fat intakes. J Am Diet Assoc 102, 58-64.

13. Birch LL (1999) Development of food preferences. Annu Rev Nutr 19, 41-62.

14. Browne M (2009) A comparative study of parental behaviors and children's eating habits. Infant Child Adolesc Nutr 1, 11-14.

15. Kremers SP (2003) Parental style and adolescent fruit consumption. Appetite 41, 43-50.

16. Rhee KE, Lumeng JC, Appugliese DP et al. (2006) Parenting styles and overweight status in first grade. Pediatrics 117, 2047-2054.

17. Bauer K, Nelson M, Boutelle K et al. (2008) Parental influences on adolescents' physical activity and sedentary behavior: longitudinal findings from Project EAT-II. Int $J$ Behav Nutr Phys Act 5, 12.

18. Campbell KJ, Crawford DA, Salmon J et al. (2007) Associations between the home food environment and obesity-promoting eating behaviors in adolescence. Obesity (Silver Spring) 15, 719-730. 
19. Gibson EL, Wardle J \& Watts CJ (1998) Fruit and vegetable consumption, nutritional knowledge and beliefs in mothers and children. Appetite 31, 205-228.

20. Leatherdale ST \& Wong SL (2008) Modifiable characteristics associated with sedentary behaviours among youth. Int $J$ Pediatr Obes 3, 93-101.

21. Haerens L, Craeynest M, Deforche B et al. (2007) The contribution of psychosocial and home environmental factors in explaining eating behaviours in adolescents. Eur J Clin Nutr 62, 51-59.

22. Fees B, Trost S, Bopp M et al. (2009) Physical activity programming in family child care homes: providers' perceptions of practices and barriers. J Nutr Educ Behav 41, 268-273.

23. Spurrier N, Magarey A, Golley R et al. (2008) Relationships between the home environment and physical activity and dietary patterns of preschool children: a cross-sectional study. Int J Behav Nutr Phys Act 5, 31.

24. Blanchette L \& Brug J (2005) Determinants of fruit and vegetable consumption among 6-12-year-old children and effective interventions to increase consumption. J Hum Nutr Diet 18, 431-443.

25. Kratt P, Reynolds K \& Shewchuk R (2000) The role of availability as a moderator of family fruit and vegetable consumption. Health Educ Behav 27, 471-482.

26. Saelins BE, Sallis JF, Nader PR et al. (2002) Home environmental influences on children's television watching from early to middle childhood. J Dev Behav Pediatr 23, $127-132$.

27. Salmon J, Timperio A, Telford A et al. (2005) Association of family environment with children's television viewing and with low level of physical activity. Obes Res 13, 1939-1951.

28. French SA, Shimotsu ST, Wall M et al. (2008) Capturing the spectrum of household food and beverage purchasing behavior: a review. J Am Diet Assoc 108, 2051-2058.

29. Bryant M \& Stevens J (2006) Measurement of food availability in the home. Nutr Rev 64, 67-76.

30. McKinnon RA, Reedy J, Morrissette MA et al. (2009) Measures of the food environment: a compilation of the literature, 1990-2007. Am J Prev Med 36, 4 Suppl., S124-S133.

31. Berry D, Sheehan R, Heschel R et al. (2004) Family-based interventions for childhood obesity: a review. J Fam Nurs 10, 429-449.

32. McLean N, Griffin S, Toney K et al. (2003) Family involvement in weight control, weight maintenance and weight-loss interventions: a systematic review of randomised trials. Int J Obes Relat Metab Disord 27, 987-1005.

33. Moore BA \& O'Donohue WT (2005) Examining familybased treatments for pediatric obesity: a detailed review of the last 10 years. In Psychological Approaches to Chronic Disease Management; A Report of the Fifth Reno Conference on the Integration of Behavioral Health in Primary Care, pp. 225-270 [NA Cummings, WT O'Donohue and EV Naylor, editors]. Reno, NV: Context Press.

34. Nowicka P \& Flodmark C (2008) Family in pediatric obesity management: a literature review. Int J Pediatr Obes 3, Suppl. 1, 44-50.

35. Ventura A \& Birch L (2008) Does parenting affect children's eating and weight status? Int J Behav Nutr Phys Act 5, 15.

36. Young EM, Fors SW, Fasha E et al. (2004) Associations between perceived parents behaviors and middle school student fruit and vegetable consumption. J Nutr Educ Behav 36, 2-12.

37. Hand DJ (1996) Statistics and the theory of measurement. $R$ Stat Soc Series 159, 445-492.

38. Gattshall ML, Shoup JA, Marshall JA et al. (2008) Validation of a survey instrument to assess home environments for physical activity and healthy eating in overweight children. Int J Behav Nutr Phys Act 5, 3.
39. Rosno EA, Steele RG, Johnston CA et al. (2008) Parental locus of control: associations to adherence and outcomes in the treatment of pediatric overweight. Children's Health Care 37, 126-144.

40. Hearn MD, Baranowski T, Baranowski J et al. (1998) Environmental influences on dietary behavior among children: availability and accessibility of fruits and vegetables enable consumption. J Health Educ 29, 26-32.

41. Marsh T, Cullen KW \& Baranowski T (2003) Validation of a fruit, juice, and vegetable availability questionnaire. $J$ Nutr Educ Behav 35, 93-97.

42. Cullen KW, Baranowski T, Owens E et al. (2003) Availability, accessibility, and preferences for fruit, $100 \%$ fruit juice, and vegetables influence children's dietary behavior. Health Educ Behav 30, 615-626.

43. De Bourdeaudhuij I, Klepp K, Due P et al. (2005) Reliability and validity of a questionnaire to measure personal, social and environmental correlates of fruit and vegetable intake in 10-11-year-old children in five European countries. Public Health Nutr 8, 189-200.

44. Cullen KW \& Thompson D (2008) Feasibility of an 8-week African American web-based pilot program promoting healthy eating behaviors: Family Eats. Am J Health Behav 32, 40-51.

45. Cullen KW, Baranowski T, Rittenberry L et al. (2000) Socioenvironmental influences on children's fruit, juice and vegetable consumption as reported by parents: reliability and validity of measures. Public Health Nutr 3, 345-356.

46. Fulkerson J, Nelson M, Lytle L et al. (2008) The validation of a home food inventory. Int J Behav Nutr Phys Act 5, 55.

47. van Assema P, Glanz K, Martens M et al. (2007) Differences between parents' and adolescents' perceptions of family food rules and availability. J Nutr Educ Behav 39, 84-89.

48. Hume C, Ball K \& Salmon J (2006) Development and reliability of a self-report questionnaire to examine children's perceptions of the physical activity environment at home and in the neighbourhood. Int J Behav Nutr Phys Act 3, 16.

49. Sirard JR, Nelson MC, Pereira MA et al. (2008) Validity and reliability of a home environment inventory for physical activity and media equipment. Int J Behav Nutr Phys Act 5, 24.

50. Wartella EA \& Jennings N (2000) Children and computers: new technology - old concerns. Future Child 10, 31-43.

51. Rosenberg D, Sallis J, Kerr J et al. (2010) Brief scales to assess physical activity and sedentary equipment in the home. Int J Behav Nutr Phys Act 7, 10.

52. Timperio A, Salmon J, Ball K et al. (2008) Family physical activity and sedentary environments and weight change in children. Int J Pediatr Obes 3, 160-167.

53. van Zutphen MV, Bell AC, Kremer PJ et al. (2007) Association between the family environment and television viewing in Australian children. J Paediatr Child Health $\mathbf{4 3}$, 458-463.

54. Golan M \& Weizman A (1998) Reliability and validity of the Family Eating and Activity Habits Questionnaire. Eur J Clin Nutr 52, 771-777.

55. Evans AE, Dave J, Tanner A et al. (2006) Changing the home nutrition environment: effects of a nutrition and media literacy pilot intervention. Fam Community Health 29, 43-54.

56. Pearson N, Timperio A, Salmon J et al. (2009) Family influences on children's physical activity and fruit and vegetable consumption. Int J Behav Nutr Phys Act 6, 34.

57. Cullen KW, Baranowski T, Rittenberry L et al. (2001) Childreported family and peer influences on fruit, juice and vegetable consumption: reliability and validity of measures. Health Educ Res 16, 187-200.

58. Vereecken CA, Keukelier E \& Maes L (2004) Influence of mother's educational level on food parenting practices and food habits of young children. Appetite 43, 93-103. 
59. Campbell KJ, Crawford DA \& Ball K (2006) Family food environment and dietary behaviors likely to promote fatness in 5-6 year-old children. Int $J$ Obes (Lond) 30 $1272-1280$

60. Larios SE, Ayala GX, Arredondo EM et al. (2009) Development and validation of a scale to measure Latino parenting strategies related to children's obesigenic behaviors. The parenting strategies for eating and activity scale (PEAS). Appetite 52, 166-172.

61. Neumark-Sztainer D, Wall M, Perry C et al. (2003) Correlates of fruit and vegetable intake among adolescents: findings from Project EAT. Prev Med 37, 198-208.

62. Dave JM, Evans AE, Pfeiffer KA et al. (2010) Correlates of availability and accessibility of fruits and vegetables in homes of low-income Hispanic families. Health Educ Res 25, 97-108.

63. Bryant MJ, Ward DS, Hales D et al. (2008) Reliability and validity of the Healthy Home Survey: a tool to measure factors within homes hypothesized to relate to overweight in children. Int J Behav Nutr Phys Act 5, 23.

64. Ihmels M, Welk G, Eisenmann J et al. (2009) Development and preliminary validation of a Family Nutrition and Physical Activity (FNPA) screening tool. Int J Behav Nutr Phys Act 6, 14.

65. Wilson AM, Magarey A \& Mastersson N (2007) Reliability and relative validity of a child nutrition questionnaire to simultaneously assess dietary patterns associated with positive energy balance and food behaviours, attitudes, knowledge and environments associated with healthy eating. Int J Behav Nutr Phys Act 5, 5.

66. Birch LL, Fisher JO, Grimm-Thomas K et al. (2001) Confirmatory factor analysis of the Child Feeding Questionnaire: a measure of parental attitudes, beliefs and practices about child feeding and obesity proneness. Appetite 36, 201-210.
67. Robinson TN, Kiernan M, Matheson DM et al. (2001) Is parental control over children's eating associated with childhood obesity? Results from a population-based sample of third graders. Obes Res $\mathbf{9}, 306-312$.

68. Ogden J, Reynolds R \& Smith A (2006) Expanding the concept of parental control: a role for overt and covert control in children's snacking behaviour? Appetite 47, 100-106.

69. Wardle J, Sanderson S, Guthrie CA et al. (2002) Parental feeding style and the inter-generational transmission of obesity risk. Obesity (Silver Spring) 10, 453-462.

70. Hughes SO, Power TG, Orlet Fisher J et al. (2005) Revisiting a neglected construct: parenting styles in a child-feeding context. Appetite 44, 83-92.

71. Maccoby EE \& Martin JA (1983) Socialization in the context of the family: parent-child interaction. In Handbook of Child Psychology, 4th ed., pp. 1-102 [EM Hetherington and PH Mussen, editors]. New York: Wiley.

72. Joyce JL \& Zimmer-Gembeck MJ (2009) Parent feeding restriction and child weight. The mediating role of child disinhibited eating and the moderating role of the parenting context. Appetite 52, 726-734.

73. Arredondo EM, Elder JP, Ayala GX et al. (2006) Is parenting style related to children's healthy eating and physical activity in Latino families? Health Educ Res 21, 862-871.

74. Kroller K \& Warschburger P (2009) Maternal feeding strategies and child's food intake: considering weight and demographic influences using structural equation modeling. Int J Behav Nutr Phys Act 6, 78.

75. Young KM, Northern JJ, Lister KM et al. (2007) A metaanalysis of family-behavioral weight-loss treatments for children. Clin Psychol Rev 27, 240-249.

76. Bollen K \& Lennox R (1991) Conventional wisdom on measurement - a structural equation perspective. Psychol Bull 110, 305-314. 